\title{
COMPETÊNCIAS PARA ENSINAR COM NOVAS TECNOLOGIAS
}

\section{Competences to teach with new technologies}

\section{Resumo}

Paulo Gileno Cysneiros ${ }^{1}$

Parte-se do pressuposto de que é necessário um modelo de ensino para se pensar a assimilação de novas tecnologias pela escola. Um modelo deve preencheralguns critérios: a) Representar de modo coerente o complexo ofício do professor, servindo de guia para a formação didática inicial e continuada de professores, b) Incorporar a pesquisa contemporânea sobre a atividade de ensinar e aprender, c) Ser razoavelmente difundido entre profissionais da Educação e d) Ser suficientemente detalhado para servir como ferramenta conceitual no trabalho com especialistas em informática, especialmente na construção de software educativo. Nesta perspectiva, é examinado o referencial de competências de Philippe Perrenoud, como uma ferramenta que pode orientar o pesquisador de software educativo, como também o professor de qualquernível na atividade cotidiana de ensinarcom novas e velhas tecnologias. Palavras-chave: Tecnologia Educacional; Informática na Educação; Didática Geral.

\section{Abstract}

It is assumed that a theory of teaching is necessary to the assimilation of new technologies by the school. An adequate theoretical model: a) Must represent in a coherent way the complex work of the teacher, serving as a framework for the initial training and the continuing formation of teachers, b) It must incorporate the contemporaneous research on the activity of teaching and leaming, c) It must be reasonably disseminated among education professionals, and d) It must be sufficiently detailed to be used as a conceptual tool by computer science personnel in the activity of constructing educational software. In such perspective, in this work it is examined the competence referential of the Swiss educatorPhilippe Perrenoud. Besides serving as a tool in the hands of the informatics professional, the referential may be used by the teacher in his daily activity of teaching.

Keywords: Educational Technology; Informatics in Education; General Didactics

1 Ex-Professor do Centro de Educação da Universidade Federal de Pernambuco; Professor Visitante da Universidade Estadual Vale do Acaraú, Ceará (2002-2004). Endereço para correspondência: Estrada de Aldeia, CPC, Caixa Postal 515, 54792-000 Camaragibe - PE.

E-mail: pgcysneiros@yahoo.com.br 


\section{Introdução}

Aceitando-se o pressuposto de que uma concepção de Educação, particularmente um modelo de ensino, é importante para se pensar a assimilação de novas tecnologias pelo professor e pela escola, o problema seguinte é a escolha de um modelo adequado.

Quando conversamos com professores, um comentário comum é que existem muitas teorias sobre a atividade de ensinar e aprender, sendo difícil fazer escolhas. É comum, nos cursos de formação e nos livros introdutórios, o estudo conjunto de vánios enfoques, apresentando-se, de modo superficial e desconexo, uma série de conceitos como sendo complementares. No entanto, é sabido que um enfoque eclético - onde se misturam conceitos de contextos diferentes ou mesmo epistemologicamente conflitantes - não é a melhor solução.

No tocante às novas tecnologias, a dificuldade de escolha multiplicase pelo fato de estarmos trabalhando numa fronteira entre (pelo menos) dois campos muito distintos - Educação e Informática (CYSNEIROS, 2003b). Para guiar nossa escolha, definimos alguns critérios que um modelo de ensino deve preencher:

a) Representar de modo coerente o complexo ofício do professor, servindo de guia na formação didática inicial e continuada de professores.

b) Incorporar a pesquisa contemporânea sobre a atividade de ensinar e aprender.

c) Ser razoavelmente difundido entre profissionais da Educação.

d) Ser suficientemente detalhado para servir como ferramenta conceitual no trabalho com especialistas em informática e áreas afins, especialmente na construção de software educativo.

Escolhemos o referencial de competências de Philippe Perrenoud porque preenche os critérios acima e porque reconhece que o uso de novas tecnologias é um dos domínios de competências do professor contemporâneo.

\section{0 referencial de competências de Philippe Perrenoud}

Para entendermos melhor o referencial, é necessário contextualizar seu autor e o ambiente em que foi construído.

Philippe Perrenoud é um educador suíço (com 60 anos em 2004), professor da Faculdade de Psicologia e Ciências da Educação da Universidade de Genebra. Seu sítio na Internet (http://www.unige.ch/fapse/SSE/teachers/ perrenoud/) merece ser visto. Na página inicial o visitante encontrará uma 
foto de meio corpo do autor, vestido de modo informal, fitando o observador. São disponibilizados artigos dele e de colaboradores, todos em francês.

Na última década, provavelmente Perrenoud foi o mais produtivo educador europeu em teoria da didática. Seu primeiro livro explorando a noção de competências foi publicado na França em 1997 e traduzido para o Brasil dois anos depois (1999). No livro seguinte "Dez Novas Competências para Ensinar" (2000), apresentando o referencial tratado neste nosso trabalho, estão listadas 42 auto-referências bibliográficas, com datas entre 1994 e 1998; outras nove situam-se entre 1986 e 1993. Além das duas obras sobre competências, foram publicados no Brasil outros livros e artigos de sua autoria (2001b), focalizando a profissionalização do professor e questões de avaliação em Educação.

O referencial de competências teve como matriz uma série de dozes artigos publicados entre setembro de 1997 e junho de 1998 na revista Éducateur, dirigida para professores da Suíça românica. No ano seguinte a obra foi publicada em Paris e logo depois no Brasil. Além da meia centena de autocitações bibliográficas, outras 240 referências (235 em francês e cinco em inglês) fundamentam seu trabalho sobre competências. Outros autores muito citados são Monica Gather Thurler, sua colaboradora e co-autora noutras publicações (com dez referências) e Philippe Meirieu (com treze referências), ambos com livros em português (PERRENOUD; GATHER THURLER, 2002; MEIRIEU, 2002).

Tendo sido escrito para orientar a formação continuada de professores (enseignants) em serviço, o referencial é um livro agradável de se ler, estudar e consultar de vez em quando. Obviamente, vários trechos devem ser adaptados pelo leitor brasileiro, tendo em vista nossa cultura e a situação do nosso professor, que ainda não goza do status, da formação, das condições de trabalho e de remuneração existentes em países ricos, com tradição em educação como a Suíça e a França, possuidores de sistemas educacionais bem menores e mais uniformes do que o sistema brasileiro.

Perrenoud participou da produção do referencial de competências adotado pelo governo suíço, no qual baseou-se para escrever o livro sobre dez famílias de competências. Sua produção certamente influenciou a definição de Parâmetros Curriculares Nacionais (PCNs) no governo FHC (CYSNEIROS, 2003a). No Brasil, Perrenoud tem publicado com pesquisadores brasileiros tais como Gather Thurler et. al. (2002) e suas conferências têm lotado auditórios de vários congressos sobre Educação.

\section{Uma caracterização de Competência}

Segundo Perrenoud (1999, 2000, 2001b), competência é a faculdade de mobilizar um conjunto de recursos cognitivos (saberes, capacidades, infor- 
mações, etc.) para enfrentar com pertinência e eficácia uma série de situações. É um construto teórico ancorado em várias premissas:

1. As competências não são apenas saberes, mas integram, incorporam conhecimentos adquiridos no decorrer da história de vida da pessoa. Uma idéia comum na nossa cultura é a diferença entre saber e saber fazer. Não basta saber, sendo necessário saber aplicar, mobilizar (pôr em movimento, transformar em ação visível) 0 conhecimento, quando surgirem ocasiões propícias.

2. A capacidade de mobilização de saberes só se desenvolve em situações singulares. É necessário trabalhar, exercitar a mobilização, a transferência para o cotidiano. Isso exige tempo, com erros e acertos parciais, resultando em descobertas individuais e de equipe.

Vários conceitos de Psicologia e de outras ciências estão subjacentes à idéia de ação situada. Salientamos o conceito de esquema, utilizado por vários teóricos da Psicologia, notadamente por Jean Piaget e por educadores socioconstrutivistas. Em qualquer competência, esquemas gerais de ação (mental e física) possibilitam realizar ações adaptadas a situações específicas; no caso, situações de ensino e de trabalho na escola. Essas ações podem ter desenvolvimento complexo, com origem em outras ações ou esquemas mais simples. Por exemplo, esquemas de uso pessoal de um processador de texto podem ser fundidos com esquemas de ensino de redação, originando um esquema mais complexo, relativo o uso de computadores em situações de aprendizado da língua materna.

3. Na escola não se trabalha suficientemente a transposição didática, a mobilização de capacidades, não se atribuindo tanta importância a essa prática (CYSNEIROS, 2004). Professores e alunos acumulam saberes, mas não conseguem mobilizar o que aprenderam em situações da vida, no trabalho e fora dele. Aprende-se a ler, escrever e contar, mas também a raciocinar, explicar, resumir, observar, comparar, desenhar e muitas outras capacidades gerais. Assimilam-se conhecimentos de matemática, história, ciências e outras disciplinas, mas a escola quase não ensina como ligar os saberes a situações da vida do aprendiz².

2 Quando criança, uma das coisas que sempre me intrigou foi ouvir a frase, intuitivamente contraditória, "faça o que eu digo e não faça o que eu faço". Quando estudante universitário, também me intrigava o fato de professores ilustres não utilizarem, nas aulas, as teorias de Didática e de Psicologia que ensinavam. O conceito de competência nos ajuda a entender tais situações. 
Vivemos em ambientes saturados de informações, que podem confundir mais do que ajudar, levando à dispersão, a desequilíbrios entre acumulação desorganizada de saberes e atualização de competências em situações de vida pessoal e profissional (CYSNEIROS, 2004).

Sobre a atividade de ensinar, Perrenoud enfatiza que a construção do conhecimento é uma trajetória coletiva que o professor orienta, criando situações e auxiliando o aprendiz, sem ser 0 especialista que transmite 0 saber nem o guia que propõe a solução para o problema. O professor que "dá" a matéria em uma pedagogia frontal, baseada na aula tradicional, é um profissional que tende a desaparecer.

De nossa parte, acreditamos que tal profissional dificilmente desaparecerá. Sem uma renovação profissional, fruto da formação continuada, da melhoria das condições de trabalho e remuneração, o professor tende a assimilar as novas tecnologias à sua prática tradicional sem mudanças significativas, um fenômeno que temos chamado de inovação conservadora (CYSNEIROS, 1998).

\section{Referencial de Competências}

Por questões práticas, Perrenoud (2000, 2001b) postula dez domínios de competências prioritárias para a formação de professores de nível fundamental e médio. Cada um dos dez domínios é desdobrado em quatro ou cinco competências de segundo nível, perfazendo 44 no total. Outros desdobramentos seriam possíveis, porém ao preço de perda da facilidade de utilização do referencial em situações concretas.

Neste trabalho organizamos os dez domínios de competências em quatro categorias:

I - Quatro domínios referem-se especificamente ao ensino, aos problemas perenes de qualquer didática:

1. Organizar e dirigir situações de aprendizagem (cerne do ofício do professor)

- Conhecer os conteúdos a serem ensinados e sua tradução em objetivos de aprendizagem.

- Trabalhar a partir das representações dos aprendizes.

- Trabalhar a partir dos erros e obstáculos à aprendizagem.

- Construir e planejar dispositivos e seqüências didáticas.

- Envolver os alunos em atividades de pesquisa, em projetos de conhecimento. 
2. Administrar a progressão das aprendizagens (visão longitudinal do todo)

- Conceber e administrar situações-problema ajustadas ao nível e possibilidades dos aprendizes.

- Adquirir uma visão longitudinal dos objetivos do ensino.

- Estabelecer laços com as teorias subjacentes às atividades de aprendizagem.

- Observar e avaliar os aprendizes em situações de aprendizagem, de acordo com uma abordagem formativa. - Fazer balanços periódicos de competências e tomar decisões de progressão rumando em direção a ciclos de aprendizagem.

3. Conceber e fazer evoluir dispositivos de diferenciação (evitar as mesmas lições e exercícios para todos, pois a diversidade de aprendizes é a norma).

- Administrar a heterogeneidade no âmbito de uma turma. - Abrir, ampliar a gestão de classe para um espaço mais amplo. - Fornecer apoio integrado e trabalhar com aprendizes portadores de grandes dificuldades.

- Desenvolver a cooperação entre os alunos e formas simples de ensino mútuo.

4. Envolver os alunos em suas aprendizagens e em seu trabalho (motivação)

- Despertar o desejo de aprender, explicitar a relação com o saber, o sentido do trabalho escolar e desenvolver a capacidade de auto-avaliação.

- Instituir um conselho de alunos e negociar tipos de regras e de contratos.

- Oferecer atividades opcionais de formação.

- Favorecer a definição de um projeto pessoal do aprendiz.

\section{como instituição:}

II - Três domínios focalizam a atividade do professor na escola

5. Trabalhar em equipe (cooperar com colegas, especialistas, administradores)

- Elaborar um projeto em equipe e representações comuns.

- Dirigir um grupo de trabalho, conduzir reuniões.

- Formar e renovar uma equipe pedagógica.

- Enfrentar e analisar em conjunto situações complexas, práticas

e problemas profissionais.

- Administrar crises e conflitos interpessoais. 
6. Participar da administração da escola (não ficar apenas na sala de aula)

- Elaborar e negociar um projeto de instituição.

- Administrar os recursos da escola.

- Coordenar e dirigir uma escola com todos os seus parceiros.

- Organizar e fazer evoluir, no âmbito da escola, a participação dos alunos.

- Trabalhar em ciclos de aprendizagem.

7. Informar e envolver os pais (em relacionamentos de parceria)

- Dirigir reuniões de informação e de debate.

- Fazer entrevistas, ouvir e compreender, negociar.

- Envolver os pais na construção de saberes, sem temores ou subterfúgios, considerando-os como parceiros.

III - Dois domínios são relativos ao próprio educador:

8. Enfrentar os deveres e os dilemas éticos da profissão - Prevenir a violência na escola e fora dela. - Lutar contra preconceitos e discriminações sexuais, étnicas e sociais.

- Participar da criação de regras comuns referentes à disciplina na escola, às sanções e à apreciação da conduta.

- Analisar a relação pedagógica, a autoridade e a comunicação em aula.

- Desenvolver o senso de responsabilidade, a solidariedade e 0 sentimento de justiça.

9. Administrar sua própria formação contínua - Saber explicitar as próprias práticas.

- Estabelecer seu próprio balanço de competências e seu programa pessoal de formação contínua.

- Negociar um projeto de formação comum com os colegas (equipe, escola, rede).

- Envolver-se em tarefas em escala de uma ordem de ensino (fundamental ou médio) ou do sistema educativo local, regional e nacional.

- Acolher a formação dos colegas e participar dela.

- Ser agente do sistema de formação contínua.

IV - Um último domínio abrange as categorias anteriores.

10. Utilizar Novas Tecnologias da Informação e Comunicação

Aqui Perrenoud destaca quatro competências de segundo nível:

- Utilizar editores de texto. 
- Explorar a potencialidade didática de aplicativos.

- Comunicar-se à distância por meio da telemática.

- Utilizar ferramentas multimídia no ensino.

Como esta última família de competências trata de uma área em mutação, com o constante surgimento de novas ferramentas e sobre as quais muitas coisas interessantes (e outras questionáveis) têm sido escritas, consideramos que merece revisão dentro do próprio modelo. O capítulo que trata deste tema foi escrito em abril de 1998, quando as novas tecnologias da informação não tinham a maturidade que têm hoje.

Além disso, com notável honestidade intelectual, no último capítulo do livro sobre o referencial, utilizando a metáfora de uma viagem, Perrenoud reconhece ter conduzido o leitor "em uma jornada rápida e um pouco superficial" por lugares que mereceriam uma estada mais longa: :

... Alguns dos continentes (famílias de competências) e dos países (competências específicas) eu os percorri muitas vezes. De alguns outros, tenho uma idéia menos precisa, conhecimentos de segunda mão. Alguns me apaixonam, outros menos... (PERRENOUD, 2000, p.171).

É possível que um dos "continentes" pouco vividos tenha sido o domínio de tecnologias. Um dos indicadores desta suposição é que as autoreferências, apenas duas, com datas de 1992 (quando não havia Internet) e 1998, tratam do uso de novas tecnologias na educação.

\section{Uma Concepção Equilibrada de Novas Tecnologias na Educação}

Perrenoud enfatiza a necessidade de uma reflexão crítica, equilibrada, sobre as novas tecnologias, algo que também temos feito aqui no Brasil (CYSNEIROS, 1998; 2000).

Um dos pontos mencionados por ele é uma visão "curta e ingênua" da transferência didática, postulada por alguns defensores das novas tecnologias na educação. Nós temos interpretado isto como resultado de uma atitude de encantamento com novos objetos técnicos e suas novas representações da realidade (CYSNEIROS, 2003b).

No entanto, o próprio Perrenoud, como todos nós, parece não ter estado livre do canto da sereia do potencial de novas tecnologias, quando escreveu que:

... será ultrapassado pendurar dois ou três mapas geográficos nas salas de aula quando todas elas dispuserem de um meio de projetar em tela imagens do mesmo tamanho, ou equiparcada local de trabalho com um monitorde vídeo. Assim professores e alunos terão acesso a todos os mapas imagináveis, 
políticos, físicos, econômicos, demográficos, com possibilidades ilimitadas de mudança de escala e de passagem a textos explicativos ou a animações, até mesmo a imagens diretas de satélite. (2000, p.129).

Embora não sendo especialista na didática da Geografia, não estamos convencidos disto, mesmo que tal potencial seja eventualmente implementado nas escolas. Primeiro, porque temos defendido a integração de novas e velhas tecnologias na escola, do mesmo modo como tem ocorrido na vida fora da escola. Esta integração, além de desejável em termos econômicos, é recomendável do ponto de vista da construção do conhecimento pelo aprendiz. Por exemplo, mapas do bairro, da cidade, do estado, do país do aprendiz, devem sim ser pendurados nas paredes da sala de aula e nos corredores da escola, pois a exposição contínua em papel colorido de boa qualidade, exibindo a informação de forma estática, contribui para a construção de um conhecimento espacial coletivo num determinado grupo cultural. O mapa clássico é uma tecnologia que não depende de energia elétrica, sem os inconvenientes de manutenção típicos de objetos técnicos sofisticados (CYSNEIROS, 2003b).

Mas este é um ponto menor na concepção de Perrenoud sobre as novas tecnologias na educação. Eventuais atitudes de encantamento são compreensíveis. Com o passar do tempo, a assimilação do novo torna-o familiar, esvaecendo-se o deslumbramento, do mesmo modo como a alvorada de um novo dia possibilita uma visão acurada da paisagem. Um enfoque equilibrado supõe uma atividade didática integrando novas tecnologias, ambientes naturais e tecnologias simples, que tendem a passar desapercebidas devido à familiaridade, ao fato de já não serem novas, apesar de pedagogicamente subexploradas (CY SNEIROS, 2003b).

\section{Competências para Ensinar com Novas Tecnologias}

Uma leitura do referencial de Perrenoud, tendo como pano de fundo o trabalho com novas tecnologias no cotidiano da escola, dará material para um outro livro sobre o tema. Cada uma das 44 competências poderá ser examinada nesta ótica, algumas bem mais, outras menos.

Há, por exemplo, excelentes softwares educativos que exploram a primeira e a quarta família de competências, ou seja, a aprendizagem de conteúdos e de habilidades nas vánias disciplinas e a motivação para aprender. Há também ferramentas de software que podem ajudar o professor a conceber e fazer evoluir os dispositivos de diferenciação, particularmente no trabalho com aprendizes portadores de deficiências as mais diversas. 
Esta colocação não implica em atenção demasiada à tecnologia, sob o perigo de descambarmos para um novo tecnicismo.

Mesmo considerando a tecnologia como mais um dos vários adjetivos do complexo substantivo Educação, o exercício de repensar o referencial de Perrenoud face às novas tecnologias pode ser muito enriquecedor para uma equipe de professores, gerando idéias para renovação da prática escolar. Também poderá ser enriquecedor para estudantes e pesquisadores da Educação, gerando questões para projetos de grupos de pesquisa, dissertações e teses as mais diversas.

No todo, é uma construção complexa, impossível de ser feita por uma única pessoa, pois, pela própria natureza da escola, deve ser feita em equipe, incluindo gestores e professores de áreas, séries e disciplinas específicas.

\section{Considerações finais}

Perrenoud reconhece e insiste que um referencial é apenas um chão comum para o trabalho do educador (2000, Conclusões). A partir de uma base comum, cada um poderá fazer leituras diferentes do referencial. Acreditamos que isto será mais pertinente quando a leitura for feita por professores de disciplinas diversas, de culturas diferentes.

$\mathrm{O}$ autor também coloca que, embora o referencial seja apresentado como uma ferramenta de análise, ele tem uma função de síntese. A profissão do professor, em um movimento histórico, está em mutação, pois as habilidades tradicionais não são mais suficientes no mundo de hoje (PERRENOUD, 2001b). Esta colocação é particularmente adequada para os que trabalham com novas tecnologias na educação.

Embora dirigido para os níveis fundamental e médio, em linhas gerais o referencial pode ser utilizado, em maior ou menor grau, por profissionais de qualquer nível ou modalidade de ensino. Quanto ao pesquisador, particularmente aquele que trabalha com design e construção de software educativo, o uso de um referencial evitará a tendência à concentração de objetivos apenas nas competências tradicionais de ensinar e aprender.

Finalmente, vale repetir, um referencial é uma ferramenta de consulta, tanto para o profissional de educação como para o pesquisador. 


\section{Referências}

CYSNEIROS, Paulo G. Novas tecnologias na sala de aula: melhoria do ensino ou inovação conservadora? In: ENDIPE. Anais... Águas de Lindóia, 1998. v. 1. p 199-216.

. Iniciação à Informática na Perspectiva do Educador. Revista Brasileira de Informática na Educação, Florianópolis, n.7, p. 49-64, Set. 2000.

. Gestão Escolar, Parâmetros Curriculares e Novas Tecnologias na Escola. In: E. F. Ramos; M. C. Rosatelli; R. S. Wazlawick. Informática na Escola: um olhar multidisciplinar. Fortaleza: editora da UFC, 2003a.

- Fenomenologia das Novas Tecnologias na Educação. Revista da FACED, n.7, Salvador, 2003b.

. Novas Tecnologias, Informação e Educação. Educação e Sociedade: CEDES, Campinas, n. 86, Abr. 2004.

MEIRIEU, Philippe. A Pedagogia entre o dizer e o fazer: a coragem de começar. Porto Alegre: ArtMed, 2002.

PERRENOUD, Philippe. Construir as competências desde a escola. Porto Alegre: ArtMed, 1999.

. Dez novas competências para ensinar: convite à viagem. Porto Alegre: ArtMed, 2000.

. Dez novas Competências para uma nova profissão. Pátio Revista Pedagógica. Porto Alegre, n.17, p.8-12, Mai./Jul 2001a.

. Ensinar: agir na urgência, decidir na incerteza. 2. ed. Porto Alegre: ArtMed, 2001b.

PERRENOUD, Philippe; GATHER THURLER, Monica. As competências para ensinar no século XXI - formação dos professores e o desafio da avaliação. Porto Alegre, ArtMed, 2002.

. GATHER THURLER, Mônica; MACEDO, Lino de; MACHADO, Nilson José; ALESSANDRINI, Cristina Dias Formação de Professores Profissionais. Porto Alegre, ArtMed., 2002. 